\title{
Exposure to trichloramine and respiratory symptoms in indoor swimming pool workers
}

\author{
J.H. Jacobs*, S. Spaan*, G.B.G.J. van Rooy*\#, C. Meliefste*, V.A.C. Zaat*, , \\ J.M. Rooyackers*,\#, and D. Heederik*
}

ABSTRACT: The association between swimming pool characteristics and activities of employees and respiratory symptoms in employees was studied. Trichloramine levels were measured to evaluate relationships with pool characteristics and to estimate long-term exposure levels.

Questionnaires were available from 624 pool workers and 38 swimming facilities. Chloramine levels were measured by area sampling over 2-h periods and analysed using ion chromatography. Work-related and general respiratory symptoms, and symptoms indicative of atopy and bronchial hyperresponsiveness were considered. Respiratory symptom prevalence among pool workers was compared with symptoms in a Dutch population sample. Chloramine levels were modelled with regression analysis. This model was used to estimate long-term average chloramine levels for each pool studied.

Employees with higher exposure reported upper respiratory symptoms with greater frequency. Upper respiratory symptoms were statistically significantly associated with cumulative chloramine levels (odds ratio (OR) $>1.4$ for hoarseness, lost voice, sinusitis). General respiratory symptoms were significantly elevated compared with a Dutch population sample (OR ranged 1.4-7.2).

An excess risk for respiratory symptoms indicative of asthma was observed in swimming pool employees. Aggravation of existing respiratory disease or interactions between irritants and allergen exposures are the most likely explanations for the observed associations.

KEYWORDS: Occupational asthma, swimming pools, trichloramines

wimming is considered to be a healthy activity. However, for the visitors' safety, pool water needs to be disinfected. The most frequently used disinfection method is chlorination. Besides removing pathogens, free chlorine reacts with organic matter (for example, urine, saliva and sweat) and forms a mixture of potentially harmful disinfection by-products, including chloramines [1], which are thought to be responsible for irritating effects on the respiratory tract in indoor swimming pools [2] Chloramines include the inorganic compounds monochloramine $\left(\mathrm{NH}_{2} \mathrm{Cl}\right)$, dichloramine $\left(\mathrm{NHCl}_{2}\right)$ and trichloramine $\left(\mathrm{NCl}_{3}\right)$. Trichloramine is the most volatile and is easily released into the air. It is considered to be irritating to the eye and upper airway [1]. Conditions that determine production and air levels of trichloramines are believed to depend on the degree of water chlorination, contamination of water by nitrogen-containing compounds (which depends on the number of bathers, as well as their behaviour and hygiene), water temperature, water circulation and ventilation [3, 4]. However, the chemical composition of swimming pool air is extremely complex and how these factors are associated with trichloramine levels in air is poorly understood [1].

Chlorination may cause respiratory health effects in swimming pool workers and in pool visitors, particularly children and the general public, but also in competitive swimmers. Little is known about the health hazards of exposure to trichloramines at indoor swimming pools. THICKETT et al. [5] performed a case study among two lifeguards and a swimming teacher with symptoms suggestive for occupational asthma. After provocation with trichloramines, two of them showed a decreased pulmonary function indicative of an early onset response. This study showed that specific swimming pool-induced asthma might be an occupational risk. However, the study only involved three individuals and the mechanisms remain elusive [6].

Few epidemiological surveys have examined the effects of exposure to trichloramines on
AFFILIATIONS

*Institute for Risk Assessment Sciences, Division Environmental Epidemiology, Utrecht University, ${ }^{\#}$ Netherlands Expertise Centre for Occupational Respiratory Disorders, and

•University Medical Center Utrecht, Utrecht University, Utrecht, The Netherlands.

CORRESPONDENCE

J.H. Jacobs

Institute for Risk Assessment

Sciences

Division Environmental Epidemiology

PO Box 80.178

3508 TD Utrecht

The Netherlands

Fax: 31302535077

E-mail: j.h.jacobs@iras.uu.nl

Received:

February 172006

Accepted after revision:

November 122006

STATEMENT OF INTEREST

None declared.

Online ISSN 1399-3003 
respiratory health. A study among Belgian schoolchildren claimed that visiting chlorinated pools was strongly related to the prevalence of asthma and positive exercise-induced bronchoconstriction [7]. Furthermore, a positive dose-effect relationship was found between pool attendance in adults and children and serum surfactant protein-A and -B, which are markers of lung epithelium hyperpermeability in a variety of acute or chronic lung disorders [8,9]. However, as swimming is often considered healthy for asthmatics, especially for children, asthma-related referral to improve their general condition might play a role in exacerbating their symptoms and the meaning of changes in biomarker levels is unclear [6]. The analysis made use of an ecological approach and thus might have led to artificial relationships between the studied end-points and pool attendance. Moreover, the strength of the association and the statistical significance can be biased by this design [10].

MASSIN et al. [3] studied the relationship between trichloramine air levels and irritant and chronic respiratory symptoms, indices of lung function and bronchial hyperresponsiveness (BHR) in 334 French lifeguards. No associations were found between exposure and BHR, chronic bronchitis and asthma. Trichloramine exposure was significantly associated with upper respiratory symptoms. In that study, no comparison was made with the general population. Furthermore, despite the large number of chloramine measurements, no associations were studied between chloramine levels and basic characteristics, such as the number of bathers, disinfection methods and (free) chlorine concentrations in the water.

As a result of an alert from the Netherlands Center for Occupational Diseases about the urgency to study prevalence and causes of occupational asthma, the Ministry of Social Affairs and Employment decided to initiate a study in Dutch pool workers. In the present study, trichloramine levels were measured and analysed. Furthermore, associations were studied between several swimming pool characteristics, activities of workers and prevalence of self-reported health symptoms in pool workers. Respiratory symptoms in pool workers were also compared with respiratory symptoms among the general Dutch population.

\section{MATERIALS AND METHODS Population and design}

In the present cross-sectional survey, a random sample was taken using a statistical analysis programme from all 500 public indoor swimming facilities in the Netherlands, stratified by size. A complete list of swimming facilities was obtained from the National Institute for Recreation and Leisure. The management of 60 facilities was approached to complete a company checklist that provides information about the swimming pools. Furthermore, 1,066 questionnaires with an informed consent form were distributed to the employees. Three swimming facilities (52 employees) and 19 individual pool workers were self-selected into the study owing to the presence of publicity in a branch magazine. As the prevalence of respiratory symptoms did not differ from the large study population, they were added to the study base.

To obtain insight in trichloramine exposure in pools and evaluate determinants of exposure, exposure was assessed by performing a series of chloramine measurements in a sample of the study population.

As the questionnaire and exposure study were noninvasive in character, no ethical approval was required under Dutch law.

\section{Measurements of trichloramine levels}

Six swimming facilities were selected on the basis of selfreported environmental conditions (experienced temperature, ventilation, chlorine and chemicals in the air, humid and warm environment), i.e. the three facilities with the highest percentage of employees reporting an uncomfortable working environment and the three swimming facilities with the least workers complaining about environmental conditions.

The concentration of trichloramine in the pool atmosphere was measured over three consecutive 2 -h periods during 1 day. In one swimming facility, 5-day measurements were performed to study possible variation in exposure levels over time and factors causing this variation. Due to the static character of the lifeguards' tasks, no individual exposure measurements were carried out. Measurement points were situated near the pool with 25-m tracks (competition pool) and the leisure pool; one measurement was carried out at $30-40 \mathrm{~cm}$ from floor level and one at a height of $1.50 \mathrm{~m}$ (breathing zone).

The method used for sampling and analysis of trichloramine was that described by HERY et al. [4]. Trichloramines were sampled using Gilian Gilair5 pumps (Sensidyne, Clearwater, FL, USA) with a flow of $1.2 \mathrm{~L} \cdot \mathrm{min}^{-1}$. A $37-\mathrm{mm}$ cellulose support filter, with a $37-\mathrm{mm}$ Teflon filter to prevent chloride from airborne water droplets from being included in the sample, and two 37-mm quartz fibre filters, of which one was placed as a back-up filter, both impregnated with $500 \mu \mathrm{L}$ of a solution of diarsenic trioxide $\left(4 \mathrm{~g} \cdot \mathrm{L}^{-1} \mathrm{As}_{2} \mathrm{O}_{3}\right)$, sodium carbonate $\left(40 \mathrm{~g} \cdot \mathrm{L}^{-1} \mathrm{Na}_{2} \mathrm{CO}_{3}\right)$ and glycerol $\left(40 \mathrm{~mL} \cdot \mathrm{L}^{-1} \mathrm{C}_{3} \mathrm{H}_{8} \mathrm{O}_{3}\right)$, were placed in a sampling cassette. After sampling, the impregnated filters were desorbed in 10-mL ultra-high quality, ultra-pure water (specific conductivity $<17.8 \mathrm{M} \Omega \cdot \mathrm{cm}^{-1}$ at $25^{\circ} \mathrm{C}$ ), sonicated for $30 \mathrm{~min}$ and centrifuged for $15 \mathrm{~min}$ at $3,000 \times g$. Trichloramines were reduced to chlorides and subsequently analysed by ion chromatography (Dionex DX100; Dionex BV, Bavel, the Netherlands; AS14A guard and AS14 highly selective anion column with self-regenerating suppressor; conductivity detector; flow rate $\left.1.0 \mathrm{~mL} \cdot \mathrm{min}^{-1}\right)$. Temperature, relative humidity, number of swimmers in the pool water during air sampling, water temperature, $\mathrm{pH}$, free chlorine concentrations, frequency of filter refreshment of the water purification system, size of the pool and of the space around the pool were registered.

\section{Questionnaires}

The questionnaire contained information about lifestyle, workrelated conditions and several health-related symptoms. Questions about common respiratory symptoms and allergies were derived from questionnaires used in the European Community Respiratory Health Survey [11]. Work-related symptoms and dermal symptoms came from standard questionnaires developed previously [12, 13]. Symptoms were considered work-related when they occurred during or after a work shift. General respiratory symptoms, work-related respiratory symptoms and symptoms indicative for the 
presence of atopy and BHR were the health outcomes of interest. Atopy and BHR were defined on the basis of questionnaire items involving common allergies (allergies to pets, grasses, trees and house dust mites) and BHR-like symptoms (respiratory symptoms when moving from cold to warm or from warm to cold air, from cooking fumes, cigarette smoke, etc.). The company checklist contained general and technical information about building characteristics, number of visitors, information about pools, temperature of the air and water, ventilation of the building, water purification, etc.

\section{Comparison with ELON}

Prevalence for common respiratory symptoms was compared with information from a random sample $(2,711$ people) of the general Dutch population. These symptoms originated from the Dutch Respiratory Health Study (ELON; Europees Luchtweg Onderzoek Nederland [European Respiratory Health Study the Netherlands]) [11], which is part of the European Community Respiratory Health Survey.

\section{Statistical analyses}

The association between different swimming pool and employee characteristics and reported health symptoms was calculated using a multilevel analysis, which also allowed for adjustment for potential swimming pool-level effects. The level of statistical significance was set at $\mathrm{p}<0.05$. Multilevel analyses were also performed to compare asthmatic symptoms of pool workers with the ELON population and to test for an association of chloramine levels with symptoms. Associations were adjusted for smoking, sex and age.

Employees from the randomly selected swimming facilities and the three added facilities did not appear to differ significantly with regard to their respiratory symptoms. Therefore, their results were analysed together. After analysing atopic and nonatopic individuals separately, no evidence of effect modification for respiratory symptoms was present; therefore, these results are not presented in detail.

As chloramine levels were normally distributed, the arithmetic mean of the exposure measurements was calculated for leisure and competition pools and were compared using paired t-tests $(\mathrm{p}<0.05)$. To assess associations between measured chloramine levels and pool characteristics (number of visitors, kind of pool, free chlorine concentrations in water, distance between water level and ceiling (ceiling height), disinfection method, humidity, temperature), mixed regression models were used to correct for potential correlations between repeated measurements. This model was subsequently used to produce estimates of long-term average chloramine concentrations in each swimming facility, based on the 3-month average free chlorine water levels obtained for the pool and the long-term average number of visitors. Subsequently, associations between these chloramine levels and reported health symptoms were studied. Cumulative chloramine exposures were calculated by multiplying estimated chloramine levels by the number of working hours per week for each individual.

\section{RESULTS}

\section{General information}

Swimming pool characteristics are outlined in table 1. Participating swimming facilities (38 facilities) were mainly built in the 1980s and the number of visitors ranged 45,000840,000 people per year. Most of the studied pools used sodium hypochlorite for water disinfection (76\%), $11 \%$ produced chlorine by salt electrolysis and two (5\%) swimming facilities used both methods. One pool used ozone in addition to sodium hypochlorite. Pool-employee characteristics are given in table 2. Employees worked an average of $10 \mathrm{yrs}$ at the same swimming facility.

From the 1,066 pool employees, 627 (59\%) returned the questionnaire, of which 624 were used for analyses. Most of the pool workers were female, nonsmokers and worked parttime. Full-time workers were mainly male. Pool workers had a mean age of 40.5 yrs.

\section{Exposure measurements}

Three swimming facilities used electrolysis to generate chlorine; two of these were facilities with a high percentage of employees regularly reporting poor environmental conditions. The other three facilities used hypochlorite only for disinfection. Altogether, 120 air samples were taken and 119 samples were available for statistical analysis. Average and highest chloramine concentrations were 0.56 and $1.34 \mathrm{mg} \cdot \mathrm{m}^{-3}$, respectively (table 3 ). Levels were somewhat lower in leisure pools than in competition pools, although not statistically significant, and concentrations did not depend on sampling height. Low and high chloramine levels differed by less than a factor five ( 0.19 and $1.07 \mathrm{mg} \cdot \mathrm{m}^{-3}$ at 5 and $95 \%$, respectively), thus the distribution in trichloramine levels was relatively narrow. Variation in trichloramine levels over time was less than a factor 2. Regression analysis (table 4) showed that visitor numbers were significantly associated with trichloramine levels. An increase of 50 bathers was associated with a $0.40 \mathrm{mg} \cdot \mathrm{m}^{-3}$ increase in trichloramine level. Furthermore, free chlorine in water and the height of the ceiling were significantly associated with trichloramine levels (both $p<0.001)$. Analyses showed higher levels of trichloramine in pools where disinfection of water took place with sodium hypochlorite $\left(0.63 \mathrm{mg} \cdot \mathrm{m}^{-3}\right)$ compared with pools where chlorine was produced by electrolytic generation $\left(0.54 \mathrm{mg} \cdot \mathrm{m}^{-3}\right)$. However, this difference was not statistically significant after adjustment for ceiling height $(\mathrm{p}=0.20)$. Furthermore, no higher trichloramine concentrations were found in facilities where many workers reported uncomfortable environmental conditions and no associations were found between trichloramine levels and measured air temperature and humidity. As ceiling height was not known for each pool, this variable was not included in the model to estimate long-term average air trichloramine concentrations (table 4). Estimated trichloramine levels ranged $0.38-1.10 \mathrm{mg} \cdot \mathrm{m}^{-3}$, with an average concentration of $0.66 \mathrm{mg} \cdot \mathrm{m}^{-3}$.

\section{Questionnaire study}

General respiratory symptoms, atopy and BHR differed little between job categories (table 5). Reception, catering and management employees formed the reference group, for whom the potential exposure was considered lowest. Swimming instructors mainly reported work-related symptoms, particularly of the upper airways, including sinusitis (odds ratio (OR) $(95 \%$ confidence interval (CI) 2.4 (1.2-4.9)), chronic cold (3.4 (1.2-10.1)) and sore throat (2.4 (1.2-4.5)). Employees 
TABLE 1 Descriptive characteristics of the swimming pool

\begin{tabular}{lcc} 
& Total & Minimum-maximum value \\
\hline Swimming pool $\mathbf{n}$ & 38 & \\
Age swimming pool $\mathbf{y r s}$ & $28.6 \pm 16.8$ & $1.00-87$ \\
Number of visitors $\cdot \mathbf{y r}^{-1}$ & $202531 \pm 143011$ & $45000-840000$ \\
Employees $\mathbf{n}$ & $29.0 \pm 15.1$ & $7-67$ \\
Part-time employees \% & $70.2 \pm 21.1$ & $15-95$ \\
Pools per swimming facility $\mathbf{n}$ & $3.3 \pm 1.4$ & $1.00-6.00$ \\
Total water surface $\mathbf{m}^{2}$ & $736.4 \pm 703.0$ & $186-3575$ \\
Surface largest basin $\mathbf{m}^{2}$ & $432.1 \pm 341.1$ & $160-1800$ \\
Disinfection by chlorine & $29(76)$ & $11(29)$ \\
Disinfection by electrolysis & $1(3)$ & \\
Disinfection by ozone & $0.66 \pm 0.15$ & $0.38-1.10$ \\
Estimated chloramine concentration & $\mathbf{~} \mathbf{~} \mathbf{g} \cdot \mathbf{m}^{-\mathbf{3}}$ & \\
\hline
\end{tabular}

Data are presented as $\mathrm{n}$, mean $\pm \mathrm{SD}$ or $\mathrm{n}(\%)$, unless otherwise indicated. ${ }^{*}$ : calculated according to the regression model developed in the present study.

who combined the jobs of pool attendant and instructor also reported more work-related symptoms, mostly upper respiratory symptoms, and symptoms associated with rhinitis, such as a stuffed or runny nose, sneezing and itchy and watery eyes (ORs range 2.2-3.7). Reported environmental conditions (unpleasant temperature, insufficient ventilation, discomfort due to the presence of chemicals and/or chlorine in the air, too high humidity) were strongly associated with respiratory and allergic symptoms. Respiratory symptom prevalence was 1.4-4.6 times higher in people reporting poor environmental conditions (data not presented). No associations were found between estimated long-term trichloramine levels and symptoms. However, cumulative long-term trichloramine levels were significantly associated with mainly upper respiratory symptoms (ORs $\sim 1.4$ )

TABLE 2 Descriptive characteristics of the swimming pool employees

\begin{tabular}{|c|c|c|c|}
\hline Sex & $624(100)$ & $240(38)$ & $384(62)$ \\
\hline Ex-smoker & $153(25)$ & $53(22)$ & $100(26)$ \\
\hline Age yrs & $40.5 \pm 11.6(16-67)$ & $40.2 \pm 12.4(16-64)$ & $40.7 \pm 11.0(17-67)$ \\
\hline Years working at the pool & $9.8 \pm 8.7(0.10-36.1)$ & $11.1 \pm 10.4(0.10-36.1)$ & $9.0 \pm 7.4(0.10-32.7)$ \\
\hline $12-19 \mathrm{~h}$ & $117(19)$ & $18(8)$ & $99(26)$ \\
\hline 20-32 h & $182(29)$ & $28(12)$ & $154(41)$ \\
\hline $33-40 \mathrm{~h}$ & $215(35)$ & $150(63)$ & $65(17)$ \\
\hline$>40 \mathrm{~h}$ & $29(5)$ & $24(10)$ & $5(1)$ \\
\hline \multicolumn{4}{|l|}{ Job description } \\
\hline Technician & $27(4)$ & $25(10)$ & $2(1)$ \\
\hline Reception/pay desk & $41(7)$ & 0 & $41(11)$ \\
\hline Catering employee & $23(4)$ & $5(2)$ & $20(5)$ \\
\hline Combination reception/catering & $16(3)$ & $2(1)$ & $12(3)$ \\
\hline Manager/mainly office work & $60(10)$ & $37(15)$ & $23(6)$ \\
\hline Team leader & $30(5)$ & $19(8)$ & $11(3)$ \\
\hline Combination of other functions & $112(18)$ & $50(21)$ & $62(16)$ \\
\hline
\end{tabular}

Data are presented as $n(\%)$ or mean \pm SD (minimum-maximum value). 


\begin{tabular}{|c|c|c|c|c|}
\hline Overall & 119 & $19(0-80)$ & $0.56 \pm 0.25$ & $0.13-1.34$ \\
\hline Leisure pool & 59 & $23(0-80)$ & $0.54 \pm 0.27$ & $0.13-1.34$ \\
\hline Competition pool & 60 & $16(3-28)$ & $0.59 \pm 0.23$ & $0.16-1.28$ \\
\hline 30 & 59 & & $0.56 \pm 0.27$ & $0.13-1.34$ \\
\hline 150 & 60 & & $0.57 \pm 0.24$ & $0.14-1.27$ \\
\hline
\end{tabular}

Data are presented as $n$ or $n$ (minimum-maximum value), unless otherwise stated

and atopy $(\mathrm{OR}=1.4,95 \% \mathrm{CI} 1.1-1.8$; table 6). Self-reported allergy including rhinitis showed an OR of 1.6 (95\% CI 1.2-2.0; data not presented in table).

Comparison with ELON showed a statistically significantly elevated prevalence of several respiratory symptoms in swimming pool employees compared with the Dutch general population (table 7). ORs ranged from 1.4 (95\%CI 1.0-1.8) for tightness of the chest to 7.2 (95\% CI 5.2-9.9) for dyspnoea when walking with people of the same age. As expected, the symptomatology of receptionists, caterers and management employees did not differ from the Dutch population (data not presented).

\section{DISCUSSION}

Measurements of trichloramines in indoor swimming pool air showed average levels of $0.56 \mathrm{mg} \cdot \mathrm{m}^{-3}$. A statistically significant association was observed between chloramine levels and the number of swimmers, free chlorine concentration in pool water and ceiling height, probably a simple indication of the volume of air above the pool.

Elevated prevalence of particular work-related (upper) airway symptoms were observed in highly exposed swimming pool employees. Furthermore, pool workers showed more general respiratory symptoms than a Dutch population sample. Some specific indicators of asthma (physician-diagnosed asthma, asthma attacks, use of asthma medication) also occurred more frequently. Respiratory symptoms were associated with selfreported environmental conditions, but not with estimated average chloramine levels. However, cumulative chloramine concentrations were associated with some work-related upper airway symptoms.

Associations between chloramine levels and several pool characteristics are in line with earlier studies. Chloramine levels have been associated with ceiling height and free chlorine concentration in the water $[7,14]$. In most countries regulations for use of chlorine exist which are mainly focused on pool water quality. Levels of free chlorine in water of Dutch indoor swimming pools have to be $0.5-1.5 \mathrm{mg} \cdot \mathrm{L}^{-1}$. In general, all studied swimming facilities followed these quality standards. Chlorine ranges in many other countries are similar to these values. Only Germany uses lower limits $\left(0.3-0.6 \mathrm{mg} \cdot \mathrm{L}^{-1}\right)$ [1].

No regulations exist for air quality in swimming pools. HERY et al. [4] postulated a comfort level of $0.50 \mathrm{mg} \cdot \mathrm{m}^{-3}$ for trichloramine levels in the air. This level was based on the findings that at concentrations $<0.50 \mathrm{mg} \cdot \mathrm{m}^{-3}$ no irritating effects were reported. This value was confirmed in animal studies, although the details of the rationale are unclear [15]. Measured chloramine levels in the present study exceeded this comfort level regularly. MASsin et al. [3] found average concentrations of $0.67 \mathrm{mg} \cdot \mathrm{m}^{-3}$ chloramine in leisure pools, which are of the same magnitude as present findings, and $0.24 \mathrm{mg} \cdot \mathrm{m}^{-3}$ chloramine in public pools. Hery et al. [4] found approximately similar values $\left(0.64\right.$ and $0.27 \mathrm{mg} \cdot \mathrm{m}^{-3}$, respectively). This indicates that compliance with water quality regulations may lead to proposed comfort levels being exceeded. To avoid respiratory symptoms in pool employees, exposure levels may need to be lowered and additional

TABLE 4 Factors affecting the trichloramine concentrations in the air

\begin{tabular}{|c|c|c|c|c|c|c|}
\hline \multirow[t]{2}{*}{ Variable } & \multicolumn{3}{|c|}{ Without height of ceiling } & \multicolumn{3}{|c|}{ Including height of ceiling } \\
\hline & $\beta$ & SD & p-value & $\beta$ & SD & $p$-value \\
\hline Bathers $\mathbf{n}$ & 0.006280 & 0.001174 & $<0.0001$ & 0.01210 & 0.002132 & $<0.0001$ \\
\hline Free chlorine in water $\mathrm{mg} \cdot \mathrm{L}^{-1}$ & 0.3319 & 0.04803 & $<0.0001$ & 0.4152 & 0.09042 & $<0.0001$ \\
\hline
\end{tabular}


TABLE 5 Association between job and general respiratory symptoms, work-related symptoms, atopy and bronchial hyperresponsiveness (BHR), adjusted for age, smoking and sex\#

\begin{tabular}{|c|c|c|c|c|c|}
\hline & Pool attendant & Swimming instructor & $\begin{array}{l}\text { Combination } \\
\text { attendant/ } \\
\text { instructor }\end{array}$ & Cleaner & Technician \\
\hline \multicolumn{6}{|l|}{ General respiratory symptoms } \\
\hline Problems with breathing? & $2.2(0.9-5.7)$ & $2.1(1.2-3.5)^{*}$ & $2.6(1.4-4.9)^{*}$ & $2.4(0.8-7.5)$ & $1.7(0.6-4.6)$ \\
\hline Yes, constantly & $2.5(0.1-48.8)$ & $1.7(0.4-6.7)$ & $4.6(0.8-24.9)$ & $2.1(0.4-10.3)$ & $1(0.1-13.3)$ \\
\hline Cough during last 12 months & $1.8(0.5-6.3)$ & $3.5(1.6-7.3)^{*}$ & $2.9(1.3-6.6)^{*}$ & $4.1(1.1-14.7)^{\star}$ & $1.3(0.4-4.3)$ \\
\hline Phlegm during last 12 months & $2(0.6-6.9)$ & $2.6(1.2-5.6)^{*}$ & $3.1(1.2-7.8)^{*}$ & $1.5(0.2-10.4)$ & $1.1(0.3-4.4)$ \\
\hline $\begin{array}{l}\text { Tightness of chest during last } \\
12 \text { months }\end{array}$ & $0.3(0-1.7)$ & $1.3(0.6-2.7)$ & $1.1(0.4-2.7)$ & $2.3(1.0-5.3)$ & $1.5(0.5-4.5)$ \\
\hline $\begin{array}{l}\text { Dyspnoea when walking on a flat } \\
\text { surface with people of the same age }\end{array}$ & $1.6(0.5-5.2)$ & $2(0.9-4.4)$ & $1.8(0.7-4.2)$ & $3.8(0.6-25.3)$ & $1.4(0.2-8.6)$ \\
\hline Have you ever had asthma? & $0.9(0.2-3.5)$ & $1(0.4-2.3)$ & $0.5(0.1-1.8)$ & $2.4(0.4-13.8)$ & $2.5(0.6-10.5)$ \\
\hline Was it doctor diagnosed? & $0.9(0.2-4.1)$ & $1(0.4-2.5)$ & $0.3(0.1-1.6)$ & $1.6(0.1-21)$ & $2.1(0.4-10.8)$ \\
\hline Asthma attack during last 12 months & NR & NR & NR & NR & NR \\
\hline $\begin{array}{l}\text { Woken up by shortness of breath } \\
\text { during last } 12 \text { months }\end{array}$ & $2.4(0.3-17.7)$ & $1.2(0.3-4.2)$ & $1.4(0.3-5.9)$ & $2.2(0.2-20.7)$ & $0.5(0.1-4)$ \\
\hline $\begin{array}{l}\text { Shortness of breath after exercise } \\
\text { during last } 12 \text { months }\end{array}$ & $1.6(0.4-6.4)$ & $1.3(0.6-2.7)$ & $2.1(0.9-4.8)$ & $2.1(0.7-6.9)$ & $1.9(0.6-6.3)$ \\
\hline $\begin{array}{l}\text { Asthma attacks during last } 12 \text { months } \\
\text { whilst at work }\end{array}$ & NR & NR & NR & NR & NR \\
\hline $\begin{array}{l}\text { Have you ever changed work because } \\
\text { of asthma? }\end{array}$ & NR & NR & NR & NR & \\
\hline Wheeze and shortness of breath & $0.6(0.1-4.7)$ & $0.7(0.2-2.3)$ & $1.7(0.6-5.1)$ & $3.5(0.9-13.7)$ & $1.8(0.5-6.2)$ \\
\hline Shortness of breath & $1.1(0.3-4.0)$ & $1.2(0.6-2.5)$ & $2.1(>1.0-4.5)^{*}$ & $2.6(0.9-7.9)$ & $0.9(0.2-4.8)$ \\
\hline Tightness & $1.2(0.4-3.9)$ & $1.4(0.7-2.8)$ & $2.2(1.1-4.6)^{*}$ & $1.4(0.4-4.6)$ & $0.4(0.1-1.9)$ \\
\hline \multicolumn{6}{|l|}{ Upper respiratory symptoms } \\
\hline Hoarseness & NR & NR & NR & NR & NR \\
\hline Lost voice & NR & NR & NR & NR & NR \\
\hline Sinusitis & $0.7(0.3-2.1)$ & $2.4(1.2-4.9)^{*}$ & $2.3(1.0-5.6)$ & $0.4(0.1-2.9)$ & $2.0(0.7-5.7)$ \\
\hline Chronic cold & $2(0.4-10.1)$ & $3.4(1.2-10.1)^{*}$ & $3.5(1.2-10.2)^{*}$ & $1.5(0.1-15.2)$ & $1.4(0.3-6.5)$ \\
\hline Dry/sore throat & $1.2(0.5-2.9)$ & $2.4(1.2-4.5)^{*}$ & $3.2(1.7-5.9)^{*}$ & $1.1(0.4-3.2)$ & $1.6(0.5-4.5)$ \\
\hline \multicolumn{6}{|l|}{ Rhinitis } \\
\hline Blocked nose & $1.4(0.6-3.2)$ & $2.0(>1.0-3.8)^{*}$ & $3.7(1.9-7.3)^{*}$ & $1.1(0.3-3.8)$ & $2.2(0.8-5.9)$ \\
\hline Runny nose & $1.5(0.8-3.0)$ & $1.2(0.8-2)$ & $2.2(1.3-3.5)^{*}$ & $0.6(0.1-2.4)$ & $1.9(0.7-4.9)$ \\
\hline Sneezing & $1.0(0.4-2.2)$ & $2.0(1.1-3.6)^{*}$ & $2.3(1.2-4.4)^{*}$ & $1.2(0.4-3.5)$ & $2.7(1.1-6.7)^{\star}$ \\
\hline Itchy, watery eyes & $1.5(0.7-3.2)$ & $1.5(0.8-2.6)$ & $3.0(1.7-5.3)^{*}$ & $0.9(0.4-2.2)$ & $0.9(0.4-2.2)$ \\
\hline BHR & $1.2(0.4-3.4)$ & $1.6(1.0-2.8)$ & $1.3(0.7-2.5)$ & $1.0(0.3-3.4)$ & $0.9(0.2-4.0)$ \\
\hline Atopy & $1.0(0.4-2.4)$ & $1.3(0.8-2.2)$ & $0.9(0.5-1.6)$ & $1.3(0.5-3.4)$ & $0.8(0.4-1.9)$ \\
\hline
\end{tabular}

Data are presented as odds ratio (95\% confidence interval). NR: no results available due to low numbers of individuals with symptoms. ${ }^{\#}$ : management/administration, catering and reception were used as reference. *: $p<0.05$. 
TABLE 7 Comparison of general respiratory symptoms in swimming pool employees and general respiratory symptoms in the general Dutch population, ELON ( $\mathrm{n}=2711)$, adjusted for age, smoking and sex

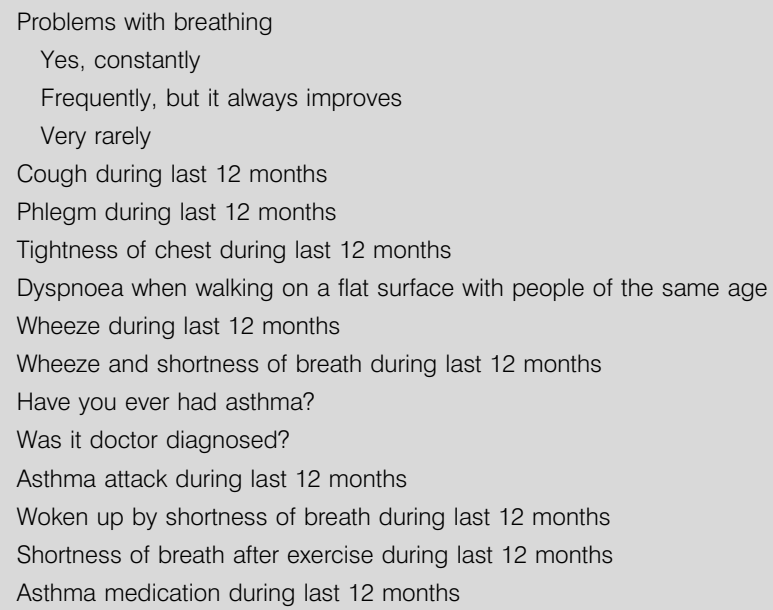

$2.2(1.8-2.8)^{*}$

$3.4(1.9-5.9)^{*}$

$1.3(1.0-1.7)$

$2.2(1.7-2.7)^{\star}$

$1.3(1.0-1.7)$

$1.8(1.3-2.4)^{*}$

$1.4(>1.0-1.8)^{\star}$

$7.2(5.2-9.9)^{*}$

$0.8(0.6-0.97)$

$0.9(0.7-1.2)$

$2.4(1.8-3.3)^{*}$

$2.1(1.5-3.0)^{*}$

$2.6(1.5-4.6)^{\star}$

$1.5(1.1-2.1)^{\star}$

$1.0(0.7-1.3)$

$3.6(2.4-5.3)^{\star}$

Data are presented as odds ratio (95\% confidence interval). ${ }^{\star}: \mathrm{p}<0.05$

exposure to chloramines, as described by THICKETT et al. [5]. The reported health symptoms were mainly problems with the throat and nose, including voice problems and sinusitis. Although a more detailed clinical evaluation is needed, cases could not be followed-up further due to privacy regulations.

Furthermore, exposure to trichloramines may cause occupational allergies and asthma through an adjuvant effect. This observation had been made earlier by PRELLER et al. $[16,17]$ in a study in farmers exposed to chloramine-T, a disinfectant. They found that chloramine- $\mathrm{T}$ was associated with elevated prevalence of atopic responses to common allergens, such as house dust mites. The authors suggested that an increased permeability of the lung epithelium by exposure to irritants might be a potential mechanism. Pool workers with high chloramine exposure more frequently reported symptoms associated with respiratory atopic disease. In addition, high trichloramine exposure was more strongly associated with selfreported allergy, including allergic rhinitis. This suggests that exposure to chloramine may act through an adjuvant effect. However, in the present study the atopic status was not based on clinical observations but on self-reported symptoms. More detailed medical characterisation is required in new studies to increase the understanding of associations between trichloramine exposure and respiratory symptoms.

Other studies have reported that exposure to irritants can cause irritation and inflammatory effects on the airways [7, 1820]. This is seen in cleaning workers, one of the high-risk groups for work-related asthma in industrialised countries. Exposure to certain chlorine-related agents and possibly also to other cleaning agents aggravates asthma symptoms in domestic cleaners [18-20]. Atopic sensitisation did not seem to play an important role in this cleaning-related asthma [18]. The present study observed elevated prevalence of (upper) respiratory symptoms; however, no differences in the prevalence of health symptoms between atopic and nonatopic individuals occurred.

\section{Limitations}

Respiratory symptoms were strongly associated with selfreported environmental conditions. However, due to the subjective nature of this factor, recall bias may have occurred. Poor environmental conditions were more often found in urban swimming facilities, but were not associated with measured trichloramine exposure. Differences in complaint behaviour between rural and urban areas might play a role. Furthermore, pool occupancy could differ between urban and rural areas. These differences can bias the outcomes of the selfreported climate conditions.

In addition, since only $60 \%$ of the pool employees completed the questionnaire, selection bias might have occurred. To check this, reported symptom prevalence in pools with a high response were compared with pools with a lower response. Prevalence did not differ, so it was assumed that there was no distortion by selection bias. Responder bias would probably be a more important limiting factor. Future studies should include objective clinical measurements, which can also give insight into relevant mechanisms explaining the excess symptoms in exposed individuals.

The differences in distribution of age, smoking habits and sex over the categories working hours per week, and the differences in distribution of these characteristics over the different job functions, can create considerable differences between crude and adjusted ORs. It is possible that this adjustment is not complete and residual confounding might be present. 
Finally, the model used to predict chloramine levels was based on only a few measurements and exposure situations. In particular, the variation in numbers of visitors was relatively small. More measurements at each facility may have produced a more accurate estimate of the chloramine levels.

\section{Conclusion}

The present study showed an elevated prevalence of airways symptoms in swimming pool workers compared with the Dutch general population. Compared with administrative staff at swimming facilities, poolside workers demonstrated more frequently work-related upper respiratory symptoms. This together with the findings that the use of asthma medication is increased indicates that, workers might be at risk of developing respiratory symptoms. It is not clear whether these pool employees developed occupational asthma related to a specific cause. Given the numbers of workers involved, irritation of the airways, including aggravation of existing asthma or modification of atopic responses, seem plausible explanations for the findings but need confirmation in other studies. Exposure to trichloramine seems to be the most important cause for the elevated prevalence of symptoms.

\section{REFERENCES}

$1 \mathrm{WHO}$, Guidelines for safe recreational-water-environment. Volume 2. Swimming pools, spas and similar recreationalwater environments. World Health Organization, Geneva, 2000.

2 Lahl U, Batjer K, Duszeln JV, et al. Distribution and balance of volatile halogenated hydrocarbons in the water and air of covered swimming pools using chlorine for water disinfection. Water Research 1981; 15: 803-814.

3 Massin N, Bohadana AB, Wild P, Hery M, Toamain JP, Hubert $G$. Respiratory symptoms and bronchial responsiveness in lifeguards exposed to nitrogen trichloride in indoor swimming pools. Occup Environ Med 1998; 55: 258-263.

4 Hery M, Hecht G, Gerber JM, et al. Exposure to chloramines in the atmosphere of indoor swimming pools. Ann Occup Hyg 1995; 39: 427-439.

5 Thickett KM, McCoach JS, Gerber JM, Sadhra S, Burge PS. Occupational asthma caused by chloramines in indoor swimming-pool air. Eur Respir J 2002; 19: 827-832.

6 Nemery B, Hoet PH, Nowak D. Indoor swimming pools, water chlorination and respiratory health. Eur Respir J 2002; 19: 790-793.

7 Bernard A, Carbonnelle S, Michel O, et al. Lung hyperpermeability and asthma prevalence in schoolchildren: unexpected associations with the attendance at indoor chlorinated swimming pools. Occup Environ Med 2003; 60: 385-394.
8 Hermans C, Bernard A. Pneumoproteinaemia: a new perspective in the assessment of lung disorders. Eur Respir J 1998; 11: 801-803.

9 Hermans C, Bernard A. Lung epithelium-specific proteins: characteristics and potential applications as markers. Am J Respir Crit Care Med 1999; 159: 646-678.

10 Armstrong B, Strachan D. Asthma and swimming pools: statistical issues. Occup Environ Med 2004; 61: 475-476.

11 Rijcken B, Kerkhof M, de Graaf M, et al. Europees Luchtweg Onderzoek Nederland. [European Respiratory Health Study the Netherlands.] Groningen Rijksuniversiteit Groningen, Epidemiologie, 1996.

12 Spaan S, Smit L, Visser MJ, et al. Blootstelling aan endotoxinen en het voorkomen van klachten bij werknemers van rioolwaterzuiveringsinstallaties. [Exposure to endotoxins and the prevalence of health symptoms in workers of sewage treatment plants.] Utrecht, The Netherlands, Stichting Toegepast Onderzoek Waterbeheer (STOWA), 2004.

13 van Wendel de Joode B. An occupational DREAM: development, evaluation, and application of a DeRmal Exposure Assessment Method. Iras, Utrecht, Universiteit Utrecht, 2004.

14 Charlier G, Burlion N, Schrooten D. Etude de la qualite de l'air des piscines visant a definir des normes pour te contrôle regulier de ces establissements. [Study of the quality of atmosphere of the swimming pools to define standards for the regular control of these establishments.] Liège, ISSeP, 2003.

15 Gagnaire F, Azim S, Bonnet P, Hecht G, Hery M. Comparison of the sensory irritation response in mice to chlorine and nitrogen trichloride. J Appl Toxicol 1994; 14: 405-409.

16 Preller L. Respiratory health effects in pig farmers. Assessment of exposure and epidemiological studies of risk factors, in Department of Epidemiology and Public Health. Wageningen, The Netherlands, Wageningen University, 1995.

17 Preller L, Doekes G, Heederik D, Vermeulen R, Voyelzang PF, Bolij JS. Disinfectant use as a risk factor for atopic sensitization and symptoms consistent with asthma: an epidemiological study. Eur Respir J 1996; 9: 1407-1413.

18 Zock JP, Kogevinas M, Sunyer J, et al. Asthma characteristics in cleaning workers, workers in other risk jobs and office workers. Eur Respir J 2002; 20: 679-685.

19 Medina-Ramon M, Zock JP, Kogevinas M, Sunyer J, Anto JM. Asthma symptoms in women employed in domestic cleaning: a community based study. Thorax 2003; 58: 950-954.

20 Medina-Ramon M, Zock JP, Kogevinas M, et al. Asthma, chronic bronchitis, and exposure to irritant agents in occupational domestic cleaning: a nested case-control study. Occup Environ Med 2005; 62: 598-606. 